\title{
Retrospective analysis of maternal mortality: a paradigm shift from 2010 to 2020
}

\author{
Sujani Kempaiah, Urvashi, Mamatha*, Jessica celina fernandes, \\ Gayatri Devi Sivasambu, Shaziya Azmathulla, Shruthi Shivashankar
}

Department of OBG, Ramaiah Medical College Hospital, Bengaluru, Karnataka, India

Received: 26 May 2021

Accepted: 30 June 2021

*Correspondence:

Dr. Mamatha,

E-mail: mamatha750@yahoo.com

Copyright: (c) the author(s), publisher and licensee Medip Academy. This is an open-access article distributed under the terms of the Creative Commons Attribution Non-Commercial License, which permits unrestricted non-commercial use, distribution, and reproduction in any medium, provided the original work is properly cited.

\begin{abstract}
Background: Maternal mortality is attributed usually to complications that generally occur during or around labour and these are mostly preventable through proper understanding, diagnosis and management of labour complications. The quality of health services women receive during pregnancy, intranatal and postnatal periods are crucial for the survival and well-being of the mother and her newborn baby. The objective was to analyse the changing trends in maternal mortality occurring over a decade, to assess factors associated with maternal mortality and propose effective interventions in preventing such mortality.

Methods: It was a retrospective study to analyse maternal mortality between January 2010 and January 2020 in Ramaiah medical college hospital. Data was collected the institutional medical and delivery records and patient details regarding obstetric history, pre-existing comorbidities, cause of death, interventions done was noted and review of maternal mortality was done.

Results: The maternal mortality in the present study was 432.73/1 lakh live births. There were 57 maternal deaths in the study period. Most deaths occurred in the $20-25$ age group. $42.10 \%$ of deaths occurred ninety six hours after admission. Sepsis $(42.1 \%)$, hypertensive disorders $(12.30 \%)$ and haemorrhage $(10.5 \%)$ are the most common direct causes of maternal death. Post-operative and post abortal sepsis, ARDS, cardiogenic shock, pulmonary embolism and AFLP are the other direct causes. Hypertensive disorders (9.64\%) and haemorrhage (19.5) is the two leading indirect causes of maternal deaths.

Conclusions: Maternal health services should move beyond the focus on emergency obstetric care, to a broader approach that encompasses preventive and early interventions and integration with existing services. Most of the maternal deaths can be prevented if the high risk antenatal women are identified earlier and referred to the tertiary centre earlier for diagnosis and management.
\end{abstract}

Keywords: Maternal mortality, Haemorrhage, Hypertensive disorders

\section{INTRODUCTION}

Maternal health has many valued outcomes but maintaining focus on maternal death is crucial in areas where the mortality burden is high. ${ }^{1}$ The five most important direct causes of maternal mortality in developing countries are haemorrhage, sepsis, unsafe abortion, eclampsia and obstructed labour. Maternal mortality in resource-poor nations has been attributed to the 3 delays like delay in deciding to seek care, delay in reaching care in time and delay in receiving adequate treatment. ${ }^{2}$ Within India, there is a marked variation in healthcare access between regions and in socioeconomic factors, accordingly, there is also variation in maternal 
deaths for various states, regions and demographics of women. ${ }^{3}$

The continuing burden of maternal mortality, especially in developing countries has prompted a shift in paradigm from the traditional risk assessment approach to the provision of access to emergency obstetric care services for all women who are pregnant. A continuous assessment of maternal mortality is required to assure the progress towards safe motherhood. ${ }^{4}$

The epidemiology of maternal mortality requires prioritisation of the intrapartum period. The other opportunities to alter the risk of maternal death include providing proper antenatal care, postpartum care, family planning and safe abortion. Better population-based sources on maternal mortality for local-level decision making are essential to achieving improved outcomes and reduce the mortality rates.

\section{METHODS}

It was a retrospective study to analyse maternal mortality between January 2010 and January 2020 in Ramaiah medical college hospital. The data was collected from the institutional medical and delivery records. All relevant patient details regarding obstetric history, pre-existing comorbidities, cause of death, interventions done was noted and review of maternal mortality was done and preventive measures was proposed.

\section{Inclusion criteria}

Death of all women while pregnant or within 42 days of termination of pregnancy, irrespective of the duration and site of the pregnancy, from any cause related to or aggravated by the pregnancy or its management were the inclusion criteria.

\section{Exclusion criteria}

Maternal death due to incidental or accidental causes were excluded from the study.

Statistical analysis was done using the statistical software namely IBM SPSS statistics version 18. All the quantitative parameters like age, BMI, scores was presented using descriptive statistics such as mean and standard deviation or median and range.

All the qualitative parameters such as education, parity, socioeconomic status, occupation, subjective outcome was presented using frequency and percentages. Descriptive statistics were used and the univariate analysis was made using a Chi squared test for categorical data.

\section{RESULTS}

A total of 57 cases of maternal mortality were encountered at our tertiary care referral hospital over the decade from January 2010 to January 2020.The maternal mortality ratio in 2010 was 445 and has shown drastic variation over the years. In the years 2010-2019 the live births were 13172 and death rate was 57 giving cumulative maternal mortality rate (MMR) of 432.73 per 100000 live birth.

\section{Demographic characteristics of the patients in the present study (Table 2)}

Majority of the maternal mortality encountered in our hospital where of women of age group 20-25 years (49.1\%) followed by women between $26-30$ years of age (31.6\%). $42.1 \%$ women were primiparous and $12.3 \%$ women had parity of 2. Majority of women belonged to upper lower socio-economic status as per modified Kuppuswamy classification. $59.6 \%$ of women lived within a radius of $10-100 \mathrm{~km}$ from the hospital with travel time being approximately less than or equal to two hours.

\section{Factors contributing to maternal mortality (Table 3)}

A total $84.2 \%$ of mortality cases had history of regular antenatal visits which was a minimum of four antenatal visits with one visit in each in first and second trimester and two visits in the third trimester. $77.2 \%$ of the cases were referred to our tertiary care hospital from other peripheral hospitals and neighbouring districts including Tumkur, Kolar, Chikkaballapur, Nelamangala, Hassan. $37.9 \%$ of the cases were referred to our hospital after delivery or caesarean for management of complications. $61.4 \%$ women were antenatal cases at the time of admission in which $26.3 \%$ of the cases were of gestational age of 28-34 weeks, $15.8 \%$ belonged to gestational age of 34 weeks 1 day to 37 weeks and $8.8 \%$ were term pregnancies.

Table 1: Year wise maternal deaths and live births.

\begin{tabular}{|llll|}
\hline Year & Maternal death & Live birth & MMR/100000 \\
\hline $\mathbf{2 0 1 0}$ & 4 & 897 & 445.63 \\
\hline $\mathbf{2 0 1 1}$ & 7 & 986 & 709.93 \\
\hline $\mathbf{2 0 1 2}$ & 5 & 1218 & 410.5 \\
\hline $\mathbf{2 0 1 3}$ & 1 & 1240 & 80.64 \\
\hline $\mathbf{2 0 1 4}$ & 11 & 1300 & 846.15 \\
\hline $\mathbf{2 0 1 5}$ & 7 & 1489 & 470.11 \\
\hline $\mathbf{2 0 1 6}$ & 4 & 1451 & 275.67 \\
\hline
\end{tabular}




\begin{tabular}{|llll|}
\hline Year & Maternal death & Live birth & MMR/100000 \\
\hline $\mathbf{2 0 1 7}$ & 7 & 1521 & 460.22 \\
\hline $\mathbf{2 0 1 8}$ & 6 & 1556 & 385.6 \\
\hline $\mathbf{2 0 1 9}$ & 5 & 1514 & 330.25 \\
\hline Total & 57 & 13172 & 432.73 \\
\hline
\end{tabular}

Table 2: Demographic characteristics of the patient.

\begin{tabular}{|lll|}
\hline Demographic characteristics & Frequency $(\mathbf{N}=\mathbf{5 7})$ & Percentage \\
\hline Age (in years) & 2 & 3.5 \\
\hline$<20$ & 28 & 49.1 \\
\hline $20-25$ & 18 & 31.6 \\
\hline $26-30$ & 6 & 10.5 \\
\hline $31-35$ & 3 & 5.3 \\
\hline$>35$ & & \\
\hline Parity & 24 & 42.1 \\
\hline Primiparous & 30 & 52.7 \\
\hline$\leq 2$ & 3 & 5.1 \\
\hline$>2$ & & \\
\hline Socio-economic status & 4 & 7.0 \\
\hline Upper middle & 18 & 31.26 \\
\hline Lower middle & 23 & 40.4 \\
\hline Upper lower & 12 & 21.1 \\
\hline Lower & & \\
\hline Distance between home and hospital (in $\mathbf{k m})$ & 17 & 29.8 \\
\hline$<10$ & 34 & 59.6 \\
\hline $10-100$ & 6 & 10.5 \\
\hline$>100$ & & \\
\hline
\end{tabular}

The common complaints that patients presented with included history of high blood pressures with complaints of imminent symptoms, jaundice, breathlessness, fever with chills, labour pains, reduced or absent fetal movements and the rest were referred in shock. $7 \%$ of the cases had multiple gestation and remaining were all singleton pregnancies. Pre-existing co-morbidities in these women included RHD, chronic hypertension, type 1 diabetes mellitus and a rare case of Fanconi's anemia.
Mode of delivery was vaginal delivery and caesarean section in $78.9 \%$ of the cases $(42.1 \%$ was vaginal mode and $36.8 \%$ under LSCS mode). $6.9 \%$ cases had abortion and the remaining $13.8 \%$ of cases succumbed antenatally. $12(21.05 \%)$ maternal deaths occurred within 24 hours of admission into the hospital. 6 (10.52\%) died within 24-48 hours. 9 (15.78\%) died within 48-72 hours and 12 (21.05\%) within 72-96 hours. $24(42.10 \%)$ died after 96 hours to $<42$ days.

Table 3: Factors contributing to maternal mortality.

\begin{tabular}{|lll|}
\hline Factors & Frequency $(\mathbf{N}=\mathbf{5 7})$ & Percentage \\
\hline Regular antenatal visits in present pregnancy & & \\
\hline Yes & 48 & 84.2 \\
\hline No & 9 & 15.8 \\
\hline Booked/referred & & \\
\hline Booked & 13 & 22.8 \\
\hline Referred & 44 & 77.29 \\
\hline Gestational age at admission (in weeks) & & \\
\hline$<28$ & 6 & 10.5 \\
\hline $28-34$ & 15 & 26.3 \\
\hline $34+1-37$ & 9 & 15.8 \\
\hline$>37$ & 5 & 8.8 \\
\hline Delivered cases & 22 & 38.6 \\
\hline Presenting complaints at admission & & \\
\hline High BP with imminent symptoms & 15 & 26.3 \\
\hline
\end{tabular}

Continued. 


\begin{tabular}{|lll|}
\hline Factors & Frequency $(\mathbf{N}=\mathbf{5 7})$ & Percentage \\
\hline Jaundice & 4 & 7 \\
\hline Breathlessness & 7 & 12.3 \\
\hline Fever with chills & 8 & 14.0 \\
\hline Haemorrhage & 3 & 5.3 \\
\hline Labour pains & 4 & 7 \\
\hline Decreased/absent fetal movements & 2 & 3.5 \\
\hline Cough with expectoration & 5 & 8.8 \\
\hline Referred in shock & 13 & 22 \\
\hline Pre-existing comorbidities & & \\
\hline RHD & 2 & 3.6 \\
\hline Chronic hypertension & 1 & 1.8 \\
\hline Fanconi's anaemia & 1 & 1.8 \\
\hline Type 1 diabetes mellitus & 1 & 1.8 \\
\hline Singleton/multiple gestation & & \\
\hline Singleton & 53 & 93 \\
\hline Twin & 4 & 7 \\
\hline Mode of delivery & & \\
\hline Abortion & 4 & 7.0 \\
\hline Vaginal delivery & 21 & 36.8 \\
\hline LSCS & 24 & 42.1 \\
\hline Not delivered (antenatal) & 8 & 14.0 \\
\hline Time interval between maternal admission and death & \\
\hline $0-24$ hours & 12 & 21.05 \\
\hline $24-48$ hours & 6 & 10.52 \\
\hline $48-72$ hours & 9 & 15.78 \\
\hline $72-96$ hours & 6 & 10.52 \\
\hline$>96$ to $<42$ days & 24 & 42.10 \\
\hline
\end{tabular}

Table 4: Care and interventions taken to prevent maternal mortality.

\begin{tabular}{|lll|}
\hline & Frequency $(\mathbf{N})$ & Percentage \\
\hline ICU admission & 57 & 100 \\
\hline Ventilator support & 36 & 63.2 \\
\hline Blood transfusion & 38 & 66.6 \\
\hline$\leq \mathbf{1 5}$ units & 22 & 38.6 \\
\hline $\mathbf{1 5}$ units & 16 & 28.1 \\
\hline Inotrope support & 27 & 47.4 \\
\hline Surgical intervention & 15 & 26.3 \\
\hline Caesarean section & 11 & 19.2 \\
\hline Exploratory laparotomy & 3 & 5.2 \\
\hline Percutaneous nephrostomy & 1 & 1.7 \\
\hline Caesarean hysterectomy & 1 & 1.7 \\
\hline Uterine artery embolization & 1 & 1.7 \\
\hline B lynch sutures & 1 & 1.7 \\
\hline Other procedures-dialysis & 3 & 5.2 \\
\hline
\end{tabular}

Table 5: Incidence and cause of maternal mortality over the decade.

\begin{tabular}{|c|c|c|c|}
\hline Year & Incidence ( $\mathrm{N}=59)(\%)$ & Direct cause (N) & Indirect cause $(\mathbf{N})$ \\
\hline \multirow{4}{*}{2010} & \multirow{4}{*}{$4(4)$} & Sepsis (2) & HDP (1) \\
\hline & & Pulmonary embolism (1) & Hemorrhage (1) \\
\hline & & HDP (1) & Swine flu (1) \\
\hline & & & RHD with $\mathrm{CCF}(1)$ \\
\hline \multirow{2}{*}{2011} & \multirow{2}{*}{$7(11.9)$} & Sepsis (5) & HDP (4) \\
\hline & & Haemorrhage (1) & Swine flu (1) \\
\hline
\end{tabular}




\begin{tabular}{|c|c|c|c|}
\hline Year & Incidence $(\mathrm{N}=59)(\%)$ & Direct cause (N) & Indirect cause (N) \\
\hline & & $\begin{array}{l}\text { Sepsis+dengue shock } \\
\text { syndrome (1) }\end{array}$ & CVA (2) \\
\hline \multirow{3}{*}{2012} & \multirow{3}{*}{$5(8.5)$} & Sepsis (2) & $\operatorname{HDP}(3)$ \\
\hline & & (1) & Haemorrhage (1) \\
\hline & & Sepsis with DIC (2) & RHD with PAH (1) \\
\hline 2013 & $1(1.7)$ & Sepsis with DIC (1) & HDP (1) \\
\hline \multirow{5}{*}{2014} & \multirow{5}{*}{$11(18.6)$} & Sepsis (6) & HDP (4) \\
\hline & & Sepsis with DIC (1) & Haemorrhage (2) \\
\hline & & Haemorrhage (2) & Metabolic encephalopathy (1) \\
\hline & & HDP (1) & ARDS (3) \\
\hline & & AFLP (1) & DIC (1) \\
\hline \multirow{5}{*}{2015} & \multirow{5}{*}{$7(11.9)$} & Sepsis (2) & $\mathrm{HDP}(5)$ \\
\hline & & Sepsis with DIC (1) & PRES (1) \\
\hline & & Haemorrhage (2) & DIC (1) \\
\hline & & HDP (1) & \\
\hline & & ARDS (1) & \\
\hline \multirow{5}{*}{2016} & \multirow{5}{*}{$4(6.7)$} & Sepsis (1) & $\operatorname{HDP}(1)$ \\
\hline & & Sepsis with DIC (1) & Haemorrhage (3) \\
\hline & & Amniotic fluid embolism (1) & RHD with PAH (1) \\
\hline & & Cardiogenic shock (1) & \\
\hline & & HDP (1) & \\
\hline \multirow{4}{*}{2017} & \multirow{4}{*}{$7(11.9)$} & Sepsis with DIC (3) & Haemorrhage (3) \\
\hline & & HDP (1) & RHD with PAH (2) \\
\hline & & Unsafe abortion (2) & SLE (1) \\
\hline & & Cardiogenic shock (1) & HDP (1) \\
\hline \multirow{4}{*}{2018} & \multirow{4}{*}{$6(10.2)$} & Sepsis (2) & Haemorrhage (2) \\
\hline & & Sepsis with DIC (2) & Swine flu (1) \\
\hline & & ARDS (1) & $\operatorname{HDP}(2)$ \\
\hline & & Haemorrhage (1) & Hemolytic anemia (1) \\
\hline \multirow{3}{*}{2019} & \multirow{3}{*}{$4(6.7)$} & Sepsis (2) & ARDS (3) \\
\hline & & HDP (1) & ITP (1) \\
\hline & & Unsafe abortion (1) & \\
\hline
\end{tabular}

Table 6: Direct and indirect causes of maternal mortality.

\begin{tabular}{|lll|}
\hline Causes & Frequency $(\mathbf{N}=59)$ & Percentage \\
\hline Direct causes & 24 & 42.1 \\
\hline Sepsis & 10 & 17.5 \\
\hline Sepsis with DIC & 7 & 12.3 \\
\hline Hypertensive disorders of pregnancy & 6 & 10.5 \\
\hline Hemorrhage & 3 & 5.3 \\
\hline Unsafe abortion & 2 & 3.5 \\
\hline ARDS & 2 & 3.5 \\
\hline Cardiogenic shock & 1 & 1.8 \\
\hline Sepsis+dengue shock syndrome & 1 & 1.8 \\
\hline Pulmonary embolism & 1 & 1.8 \\
\hline AFLP & & \\
\hline Indirect causes & 22 & 38.6 \\
\hline Hypertensive disorders of pregnancy & 11 & 19.5 \\
\hline Hemorrhage & 7 & 12.3 \\
\hline ARDS & 4 & 7 \\
\hline RHD with PAH & 3 & 5.3 \\
\hline Swine flu & 2 & 3.4 \\
\hline CVA & 2 & 3.4 \\
\hline DIC & & \\
\hline
\end{tabular}




\begin{tabular}{|lcc|}
\hline Causes & Frequency (N=59) & Percentage \\
\hline Hemolytic anemia & 1 & 1.8 \\
\hline RHD with CCF & 1 & 1.8 \\
\hline Metabolic encephalopathy & 1 & 1.8 \\
\hline Posterior reversible encephalopathy syndrome & 1 & 1.8 \\
\hline Idiopathic thrombocytopenic purpura & 1 & 1.8 \\
\hline Systemic lupus erythematosus & 1 & 1.8 \\
\hline $\begin{array}{l}\text { HDP-hypertensive disorders of pregnancy, ARDS-acute respiratory distress syndrome, AFLP-acute fatty liver of pregnancy, RHD- } \\
\text { rheumatic heart disease, CVA-cerebrovascular accident, DIC-disseminated intravascular coagulation, PAH-pulmonary arterial } \\
\text { hypertension, CCF-congestive cardiac failure. }\end{array}$
\end{tabular}

\section{Care and interventions done to prevent maternal mortality (Table 4)}

All the patients were admitted in intensive care unit, the rate being $100 \%$. $63.2 \%$ were intubated and $66.6 \%$ were required blood transfusion out of which $28.1 \%$ required massive transfusion. All measures like uterine messaging, bimanual compressions, ecbolics, uterine tamponade with condom catheter insertion were done to prevent PPH occurring due to atonic PPH. $47.4 \%$ was started on inotropic supports. $20.6 \%$ was surgically intervened out of which $17.4 \%$ underwent caesarean, $5.26 \%$ (3 patients) underwent exploratory laparotomy in which $1.7 \%$ underwent total abdominal hysterectomy. $1.7 \%$ underwent percutaneous nephrostomy due to left renal hydroureteronephrosis, 5.2\% underwent dialysis and $1.7 \%$ underwent caesarean hysterectomy. $1.7 \%$ (1 patient) had undergone uterine artery embolization due to due to atonic $\mathrm{PPH}$.

\section{Incidence and cause of maternal mortality over the decade (Table 5)}

Sepsis was the leading primary cause of death was which was $42.1 \%$ followed by sepsis with DIC which was $17.5 \%$ followed by PPH which was $10.5 \%$. Unsafe abortion and cardiogenic shock both were $5.5 \%$ and $3.5 \%$. The indirect cause of maternal death was hypertensive disorders of pregnancy which accounted for $38.6 \%$ followed by PPH which was $19.3 \%$. ARDS accounted for $12 \%$ and RHD with PAH accounted for $7 \%$ for indirect cause.

\section{DISCUSSION}

India's present MMR is below the millennium development goal (MDG) target and puts the country on track to achieve the sustainable development goal (SDG) target of an MMR below 70 by $2030 . .^{5}$ In the present study MMR varied from 330 (2010) to 445 (2019)/100000 live birth. In the last 15 years various studies in India have shown wide variation in MMR ranging from 47/100000 to $625 / 100000$ births. ${ }^{6-10}$ Jain et al has reported a very high MMR of 2270/100000. ${ }^{7}$ The extent of maternal mortality is an indicator of disparity and inequity in access to appropriate healthcare and nutrition services throughout a lifetime, and particularly during pregnancy and childbirth. ${ }^{7}$ Women who lived within a radius of 10-100 km from the hospital with travel time being approximately less than or equal to two hours were already in poor health condition when they were brought to hospital.
Women are referred too late to tertiary care centre when they develop life threatening complications which increases the maternal morbidity and mortality.

Most of the maternal death observed was $49 \%$ in $20-25$ years of age group and $31 \%$ in $26-30$ years it's similar to study by Surekha and Rao. ${ }^{12,13} 42 \%$ of death occurred in $>96$ hours of admission and $21 \%$ death occurred with 24 hours admission to hospital, it was consistent with the studies done by Rao et al and by Surekha et al. ${ }^{12,13}$ Women who were brought to hospital were already in critical health condition. All these deaths could have been avoided if they were transferred earlier emphasizing the need for adequate and quick transfer facilities.

Sepsis was the leading cause of maternal mortality in our study. The prevalence of maternal sepsis was estimated to be 16.5/10000 live birth consistent with reported rates of $0.1-0.3 \%$ for developed countries. Sepsis has very high fatality rate among pregnant women. $42 \%$ of women died of sepsis among which sepsis with DIC was seen in $17.5 \%$ and puerperal sepsis was $23 \%$.

It is similar to the study done by Kumari in which mortality due to sepsis was very high ( $80 \%$ which 35 out of 45 cases) and $31 \%$ was puerperal sepsis. ${ }^{15}$ In our study $5.3 \%$ (3 patients) died of septic abortion which was consistent with study of Khandal et al $12.5 \%$ of referral death were due to abortion many of these lives could be saved if all abortion could be performed by qualified medical personnals.

A total $12.3 \%$ of death were due to HDP in the present study which was direct cause and indirect cause being $38.6 \%$ which was similar study done by Khandal et al and by Rao et al. ${ }^{12,13}$ Early diagnosis of HDP and treatment will prevent from life threatening complications. Use of drugs like $\mathrm{Mg} \mathrm{SO} 4$ in pre-eclampsia cases can prevent patient from developing convulsion.

The second most common indirect cause of deaths in present study was haemorrhage $20 \%$ which was similar to study by Agarwal et al. ${ }^{14}$ Several publications have documented an increase in the incidence of obstetric haemorrhage particularly PPH over the recent years. It is important to identify the causative factors for obstetrical haemorrhage so that remedial measures can be taken to reduce their occurrence or severity. $\mathrm{PPH}$ also needs special attention because it can lead to death very rapidly in the absence of prompt life-saving care. ${ }^{16}$ The time available for intervention being short, demands an efficient medical 
back-up for all deliveries. Institutional deliveries should be reached to $100 \% .^{16}$

Rheumatic heart disease was the suspected cause of death in 4 cases which was $7 \%$ and pulmonary embolism was associated with $2 \%$ maternal death similar to study done by Rao et al. ${ }^{13}$ Swine flu and pneumonia (swine flu not confirmed) also accounted for the maternal death due to epidemic of H1N1 virus.

Among ICU admission, $66 \%$ of cases required mechanical ventilation. The duration of hospital stay was less than 48 hours in $32 \%$ of the cases which is consistent with study by Archana et al. ${ }^{15}$ An obstetrical procedure had to be performed in $15 \%$ of the cases similar to study by Archana et al. ${ }^{15}$

Exploratomy laparotomy was required in 3 out of 57 patients as intraperitoneal haemorrhage was noted. Out of which $1(1.7 \%)$ patient underwent total abdominal hystertetrectomy i/v/o DIC and uterine atony. 1 (1.7\%) patient underwent caesarean hysterectomy due to central placenta previa iv/o excessive bleeding intra operatively.

Haemorrhage, sepsis, eclampsia still remain the classical triad causing maternal death. All these are preventable causes of maternal mortality. Adequate treatment and timely referral services to tertiary care centres prevent most of the maternal deaths. Early detection of high risk cases, reference of these patients in time to tertiary care centre, encouraging $100 \%$ institutional delivery, improving transportation at every level can help in preventing maternal mortality rate.

\section{CONCLUSION}

Pregnancy should be viewed as a window of opportunity into the current and future health of women. It offers critical entry points for women who may otherwise not seek or have access to health care. Maternal health services should move beyond the focus on emergency obstetric care, to a broader approach that encompasses preventive and early interventions and integration with existing services. Maternal deaths due to hypertensive disorders in pregnancy, obstetric haemorrhages and sepsis can be prevented to a large extent if pregnant women attend tertiary care centre for early diagnosis and treatment. Highquality obstetric care should be made available to all women through a system of professional midwifery and referral hospital care in accountability of health care providers.

Funding: No funding sources Conflict of interest: None declared

Ethical approval: The study was approved by the Institutional Ethics Committee

\section{REFERENCES}

1. Campbell OM, Graham WJ, Lancet Maternal Survival Series steering group. Strategies for reducing maternal mortality: getting on with what works. Lancet. 2006;368(9543):1284-99.

2. Nour NM. An introduction to maternal mortality. Revs Obstet Gynecol. 2008;1(2):77-81.

3. Kaur M, Gupta M, Purayil VP, Rana M, Chakrapani V. Contribution of social factors to maternal deaths in urban India: Use of care pathway and delay models. PloS One. 2018;13(10):0203209.

4. Ijadunola KT, Ijadunola MY, Esimai OA, Abiona TC. New paradigm old thinking: the case for emergency obstetric care in the prevention of maternal mortality in Nigeria. BMC Womens Health. 2010;10(1):6.

5. Strategies toward ending preventable maternal mortality (EPMM). World Health Organization | February 2015. Available at: https://www.who.int/ reproductivehealth/topics/maternal_perinatal/epmm/en.

6. Puri A, Yadav I, Jain N. Maternal mortality in an urban care hospital of north Insia. J Obstet Gynaecol India. 2011;61(3):280-5.

7. Jain M, Maharaje S. Maternal mortality: a retrospective analysis of ten years in a tertiary care hospital. Indian J Prev Soc Med. 2003;34:103-11.

8. Jadhav AJ, Rote PG. Maternal mortality-changing trends. J Obstet Gynaecol India. 2007;57:398-400.

9. Pal A, Ray P, Hazra S, Mondal TK. Review of changing trends in maternal mortality in a rural medical college in West Bangal. J Obstet Gynecol India. 2005;55:521-4.

10. Onakewhor JU, Gharoro EP. Changing trends in maternal mortality in a developing country. Niger $\mathbf{J}$ Clin Pract. 2008;11(2):111-20.

11. Kauser R. Maternal mortality in India-magnitude, causes and concerns. Indian $\mathbf{J}$ Practis Doc. 2005;2(2):5-6.

12. Khandale SN, Kedar KV. Analysis of maternal mortality: a retrospective study at tertiary care centre. Int J Reprod Contracept Obstet Gynecol. 2017;6(4):1610-3.

13. Rao PVR Potharaju J. Maternal mortality: a retrospective study in a tertiary centre. $\mathrm{J}$ Evolut Med Dent Sci. 2015;4(14):2247-54.

14. Agrawal S. Retrospective review of maternal deaths and maternal near misses due to major obstetric haemorrhage at a tertiary care centre in India. International Journal of Reproduction, contraception, Obstetrics and Gynaecology. 2019;8(8):3431-4.

15. Kumari A, Suri J, Mittal P. Descriptive audit of maternal sepsis in a tertiary care centre of North. Int $\mathbf{J}$ Reprod Contracept Obstet Gynecol. 2018;7(1):124-7.

16. Soni M, Agrawal S, Soni P, Mehra H. Causes of maternal mortality: our scenario. J South Asian Federat Obstet Gynaecol. 2013;5(3):96-8.

Cite this article as: Kempaiah SS, Urvashi, Mamatha U, Fernandes JC, Sivasambu GD, Azmathulla S, et al. Retrospective analysis of maternal mortality: a paradigm shift from 2010 to 2020. Int J Reprod Contracept Obstet Gynecol 2021;10:3079-85. 